\title{
Literature Review: Trauma-Informed Yoga in Couples \& Family Therapy
}

\author{
Mindy Tran* \\ Yoga instructor, Alliant International University, USA
}

*Corresponding author: Mindy Tran, Yoga instructor, Alliant International University, USA.

Received Date: December 03, 2019

Published Date: December 18, 2019

\section{Introduction}

Couples and family therapists are trained to view the world from a systemic lens, meaning that they practice closely examining our clients' interpersonal relationships in addition to the clients' intrapersonal and intrapsychic view of themselves. Understanding our clients systemically means that the therapist pays attention to different aspects of their identities, such as their social location, their past experiences, their support systems, and their identities. Therapists notice how these multiple dominant systems are working simultaneously in order to provide the clients' internal world with meaning. A primary source that helps therapists better understand the client is by taking in the information that the clients tell us using their own words. As a result, much of mainstream therapy is conducted in the form of a conversation. Unfortunately for many therapy clients who have experienced trauma in their lifetime, talking with a therapist may not be enough to help the client as a whole. In addition to a client maybe having a memory of the past traumatic experience(s) that they experienced, their bodies also went through that same traumatic experience as well. Our clients' brains are organized in a way that helps us survive in stressful situations, but the outcome of survival may result in our brains prioritizing our past traumatic memories, and our bodies reacting as if those events are occurring again in the present moment Van der Kolk [1] Trauma-informed yoga, or yoga that is taught from a trauma-informed lens, is one solution to incorporating the body into the therapy process since it offers a way for the clients to explore their experiences within their bodies while giving them permission to move at their own pace. By integrating trauma-informed yoga into a client's treatment plan, therapists are able to begin addressing the client as a whole, offering them the experience of embodied awareness which, over time, can help our clients minimize their post-traumatic symptoms and feel more comfortable with living fully in the present moment.

\section{Theoretical Perspectives on Trauma-Informed Yoga}

In a survey that was conducted by Yoga Alliance in 2016 gathered information on individuals across the country who have practiced any form of yoga within the past year, and found that about thirty six million Americans, or roughly ten percent of the country's population, have practiced yoga at some point in their lives Macy D [2]. Although not everyone has practiced yoga at some point in their lives, yoga is still a household name and yoga resources are widely available to many individuals through local gyms, studios, community organizations, or on the internet. The physical yoga practice is a bottom-up approach that utilizes breathing and movement cues to invite practitioners to tune into the sensations that they are experiencing in their bodies, increasing their sense of interoception Danylchuk [3]. During yoga, the student is led by an instructor that provides various cues that invite the client to observe the ebb and flow of their own emotions while also observing the physical sensations and mental states that accompany them Forbes [4]. By introducing ways that the client can practice feeling into their bodies, they can start to develop embodied awareness where they begin to feel into their experiences in the present moment while also recognizing their own needs [5].

A trauma-informed yoga practice can be used as an intervention when working with clients who are experiencing post-traumatic symptoms because it can help address some of the somatic symptoms in the body the same way that talk therapy can address some of the cognitive issues Emerson and Hopper [6]. The principles of trauma-informed yoga are rooted in traumainformed care principles that were developed by the Center for Disease Control in partnership with the Substance Abuse and Mental Health Service Administration that was intended to help those who are in the service field, under the assumption that 
individuals more likely than not have experienced some kind of traumatic event throughout their lifetime, to be able to provide the most appropriate and responsive care possible to their clients [7]. Trauma-informed care includes five core concepts: safety, choice, collaboration, trustworthiness, and empowerment. Incorporating these principles into a yoga practice would include ensuring that the class is both physically and emotionally a safe space, utilizing invitational language that allows the client to explore different modifications and postures, working with the students to adapt the class or cues based on the student's needs, building rapport with the students, and empowering the students to take effective action to meet their needs.

In order to understand how trauma-informed yoga an effective tool can be to use in conjunction with talk therapy, it is important to understand how trauma affects the body. When a person experiences something that is traumatic, meaning that we have experienced something that was unbearable and intolerable that has also taken away our power and control, our brains and bodies will organize itself in a way that will increase their likelihood of survival [1]. During trauma, the body's natural ability to cope has been overwhelmed and as a result, the body's sympathetic nervous system, or "fight-flight-or-freeze," will kick in to prepare the body to react. Over time, if the trauma has not been properly processed by the brain's prefrontal cortex, the past trauma may begin reappearing during times when the person is otherwise safe and out of harm's way. The cluster of symptoms that are most common amongst those who have experienced trauma in the past have been categorized as Post-Traumatic Stress Disorder (PTSD) in the Diagnostic and Statistical Manual of Mental Disorders. PTSD symptoms include intrusive symptoms including nightmares or flashbacks; avoidance to people, places, or things that are associated with the trauma; cognitions and moods that are negatively altered due to the traumatic event; and changes in a person's behaviors that begin after the traumatic event [8]. In addition to a traumatic event being a one-time occurrence, other forms of trauma include complex trauma that could happen over the course of a long period of time and perpetrated by someone who has a close interpersonal relationship to the person Pleines [9], or intergenerational trauma that can pass along some specific reactions or maladaptive behaviors attributed to past traumas [10]. Regardless of the means that the trauma happened, the aftermath of symptoms is often times felt in the body just as much, if not more, than it is felt in the mind.

From a therapeutic standpoint, it is also helpful to take into account attachment theory when discussing trauma and embodiment because attachment patterns can be reflective of the individual's internal working model. An internal working model is developed through the interactions that the person has with their primary caretakers during infancy that becomes internalized. As the child grows up, they use their internal working model to help them navigate the world [11]. Having a secure attachment figure allows the child to explore their world more freely because they are aware that they have a place among their caretaker where they feel a sense of belonging [12]. This sense of belonging within securely attached children influences the child's internal working model and communicates to the child that the world is a safe place to exist. If the child had grown up in an environment where their caretaker was inconsistent or was not available, the child's internal working model may begin to expect that the world will be just as inconsistent or unavailable to them. The internal working model is also how the child learns how to react to the world, including how safe they feel to advocate for their needs, how they handle receiving from or giving to others, and also how they are able to feel their emotions. If a child did not have a sense of safety for them to feel into their emotions, then they may grow up unable to access those emotions anymore [12].

\section{Clinical Implications of Trauma-Informed Yoga for Couples \& Family Therapists}

Trauma is an extremely complex topic that has many manifestations that vary from person to person, which means that the treatment for trauma must be equally complex. Unfortunately for therapists, the use of mindfulness tools such as yoga have not been as common in the therapy room Briere \& Scott [13], but as more and more research is being done on the efficacy of these ancient practices, the more it may become integrated into treatment. When treating trauma, the therapist must view this from a systemic standpoint and consider different factors such as the person's environment, their family, their support systems, and any other strengths or weaknesses that may impact their capacity to heal. As couples and family therapists, we are able to apply this systemic lens to the intrapersonal dynamic of the client and consider the ways that the client's different parts are not working in harmony with one another. Trauma-informed yoga can be a very effective addition to the treatment plan for our clients who are working towards healing trauma because of yoga's inherent focus on the embodied experience. Even if the clients are hesitant or unwilling at first to try any kind of yoga or embodiment practice, being able to have this as an opportunity available to them and to support them in the choice that they make can be a really healing experience in itself.

\section{Reflection}

As someone who has been practicing yoga for over a decade, I can attest to the fact that yoga provides a path for its students that can create a shift in the way that they relate to their bodies. Traumainformed yoga can be a powerful tool in trauma healing and can be a refreshing change of pace from the traditional talk therapy setting. Yoga by no means can replace the importance of talk therapy, but instead it can help to extend the therapeutic process from the mind into the body and from the therapy room into the real world. For some of the clients who I work with, it is difficult for them to discuss their past traumatic experiences in fear that they will be flooded with emotions when they "go there," or some of my other clients may feel no connection to most of the physical sensations in their bodies due to their past traumatic experiences. When working with clients who have difficulty with speaking to their experience, 
I have found that being able to incorporate some movement that is influenced by trauma-informed yoga can be helpful in providing a sense of grounding and comfort for the client. I have also found it to be helpful to be aware of the trauma-informed yoga classes that are nearby, so that I can offer that resource to my clients.

\section{Conclusion}

Trauma often times will take a person away from the present moment and will intrude their lives in a way that makes them feel unsafe. Trauma survivors may have difficulties with their interpersonal relationships, self-esteem, working or going to school, and many other aspects of their lives because they are unable to overcome their post-traumatic symptoms. Trauma-informed yoga, in addition to traditional therapy, can facilitate the client's journey towards feeling embodied awareness in the present moment. As this practice begins to gain traction and show up in many more communities, it is important that couples and family therapists, and other mental health professionals, be aware of this resource. One of my reasons for going into this work of trauma-informed yoga and couples and family therapy is so that I would be able to help my clients heal from their past so that they can begin to live their lives in the present moment, and trauma-informed yoga is a tool that can bring them closer to that goal.

\section{Acknowledgment}

None.

\section{Conflict of Interest}

No conflict of interest.

\section{References}

1. Van der Kolk B (2014) The body keeps the score: Brain, mind, and body in the healing of trauma. Viking, USA.

2. Macy Dana (2016) 2016 Yoga in America Study Conducted by Yoga Journal and Yoga Alliance, USA.

3. Danylchuk L (2019) Yoga for trauma recovery. Routledge, USA.

4. Forbes B (2011) Yoga for emotional balance. Boston, Massachusetts: Shambahala Publications, USA.

5. Gyllensten AL, Skär L, Miller M, Gard G (2010) Embodied identity-A deeper understanding of body awareness. Physiother Theory Pract 26(7): 439-446.

6. Emerson D, Hopper E (2011) Overcoming trauma through yoga: Reclaiming your body. North Atlantic Books, USA.

7. Substance Abuse \& Mental Health Service Administration (2014) SAMHSA's concept of trauma and guidance for a trauma-informed approach, USA.

8. American Psychiatric Association (2013) Diagnostic and statistical manual of mental disorders, $\left(5^{\text {th }} \mathrm{edn}\right)$. American Psychiatric Association, USA.

9. Pleines KE (2019) An Attachment-Informed Approach to TraumaFocused Cognitive Behavioral Therapy. Clinical Social Work Journal, 47(4): 343-352.

10. Lünnemann MKM, Horst FCPV der, Prinzie P, Luijk MPCM, Steketee M (2019) The intergenerational impact of trauma and family violence on parents and their children. Child Abuse Negl 96: 104-134.

11. Løkkeholt T, Voss LG, Shmueli Goetz Y, Bojesen AB, Simonsen E, et al. (2019) Attachment as a Core Feature of Resilience: A Systematic Review and Meta-Analysis. Psychol Rep122(4): 1259-1296.

12. Fay D (2017) Attachment-based yoga and meditation for trauma recovery. WW Norton \& Company, USA.

13. Briere J, Scott C (2015) Principles of trauma therapy: a guide to symptoms, evaluation, and treatment, USA. 